\title{
Medical Image of the Month: Emphysematous Cystitis
}



Figure 1. Abdominal CT with contrast showing a thickened, trabeculated bladder wall containing pockets of gas consistent with emphysematous cystitis due to $E$. coli infection.

Emphysematous cystitis is a rare infection of the urinary bladder caused by gas producing organisms which can be bacterial or fungal characterized by gas collections inside the bladder wall (1). Most common organisms are E. coli, Klebsiella and Proteus are also commonly isolated. Fungi, such as Candida, have also been reported as causative organisms. Presentation range from asymptomatic up to septic shock.

Jonathon P. Mahn DO1 and Mohammad A. Mahmoud MD, DO²

${ }^{1}$ Canyon Vista Medical Center and ${ }^{2}$ Internal Medicine Residency, Midwestern University, Arizona College of Osteopathic Medicine, Canyon Vista Medical Center Tucson, AZ USA

\section{Reference}

1. Amano M, Shimizu T. Emphysematous cystitis: a review of the literature. Intern Med. 2014;53(2):79-82. [CrossRef] [PubMed] 